\title{
Interchangeability of AMT4 and AMTS in a hip fracture population
}

The Nottingham Hip Fracture Score [1] has been widely validated as a tool for prediction of outcomes following hip fracture. Since its inception, it has used the Abbreviated Mental Test Score (AMTS) of $<7 / 10$ [2] as a surrogate for acute (delirium) or chronic (dementia) cognitive impairment. More recently, the 4AT has been developed as an accurate screening tool for delirium [3]. This uses a 4-question subset of the full AMTS (AMT4) as one of its domains. The 4AT is a mandated component of the Best Practice Tariff for hip fracture care in England, and is recommended as a tool for identifying probable delirium in the emergency department [4].

As part of a local quality improvement project we wished to investigate the possibility of interchanging the AMTS component of the Nottingham Hip Fracture Score with the AMT4. This would have the advantage of matching practice to national guidance and reducing the assessment burden for patients and admitting staff. We also wished to investigate whether admission AMT4 would serve as a useful predictor of postoperative positive AMT4 scores.

Previous work has suggested adequate interchangeability [5], but in outpatient and community cohorts rather than the acute setting. These studies also used an AMTS of $<8 / 10$ as a threshold for cognitive impairment rather than $<7 / 10$ as originally described by Hodkinson et al. [2] and as used in the Nottingham Hip Fracture Score. Studies which have evaluated the use of the AMT4 in hospital inpatient cohorts have not directly assessed interchangeability with the AMTS [6].

Following local approval (NUH registration number 19-287Q), we extracted data on admission AMTS and postoperative AMT4 on a consecutive series of 200 patients admitted with hip fracture through our emergency department from January to March 2019.

The relationship between AMTS and AMT4 is shown in Figure 1. Admission AMT4 is a reasonable alternative to the full AMTS in patients admitted following hip fracture. Both are acting as pragmatic surrogates for fuller assessment of cognition so perfect correlation is not to be expected. 
The positive predictive value (PPV) and negative predictive value (NPV) of 0.82 and 0.98 , respectively, are comparable to the PPV and NPV reported by Swain et al. [5] in an outpatient population using an AMTS threshold for cognitive impairment of $<8 / 10(0.84$ and 0.96 , respectively). Using the original Swain et al. data we calculated a PPV of 0.63 and a NPV of 0.98 if an AMTS threshold of $<7 / 10$ is used, suggesting that the AMT4 in fact performs better as a substitute for the AMTS when used in an acute hip fracture population.

The predictive value of a positive admission AMT4 for a positive postoperative AMT4 is 0.72 . As illustrated in Figure 2 there is frequently a change in a patient's AMT4 peri-operatively. This highlights the importance of repeat cognitive scoring during a patient's admission and to avoid relying on admission assessment as a continuing marker of the presence of cognitive impairment.

\author{
WA Lindsay \\ IK Moppett \\ University of Nottingham, Nottingham, UK \\ @lainMoppett
}

Correspondence to: msawl5@exmail.nottingham.ac.uk

IKM is a member of the NICE topic expert group for Quality Standards for hip fracture, Deputy Director of the Health Service Research Centre of the National Institute of Academic Anaesthesia (NIAA) and holds grants from the National Institute for Health Research (NIHR) and the Association of Anaesthetists and Royal College of Anaesthetists through the NIAA for trials in hip fracture. No other external funding or competing interests declared. 


\section{References}

1. Moppett IK, Parker M, Griffiths R, Bowers T, White SM, Moran CG. Nottingham Hip Fracture Score: longitudinal and multi-centre assessment. British Journal of Anaesthesia 2012; 109: 546-50.

2. Hodkinson HM. Evaluation of a mental test score for assessment of mental impairment in the elderly. Age and Ageing 1972; 1: 233-8.

3. Bellelli G, Morandi A, Davis DHJ et al. Validation of the 4AT, a new instrument for rapid delirium screening: a study in 234 hospitalised older people. Age and Ageing 2014; 43: 496502.

4. SIGN. Risk Reduction and Management of Delirium A National Clinical Guideline. SIGN 157. March 2019. https://www.sign.ac.uk/assets/sign157.pdf (accessed 12/7/2019).

5. Swain DG, Nightingale PG. Evaluation of a shortened version of the Abbreviated Mental Test in a series of elderly patients. Clinical Rehabilitation 1997; 11: 243-8.

6. Schofield I, Stott DJ, Tolson D, McFadyen A, Monaghan J, Nelson D. Screening for cognitive impairment in older people attending accident and emergency using the 4-item Abbreviated Mental Test. European Journal of Emergency Medicine 2010; 17: 340-2.

7. R: The R Project for Statistical Computing. https://www.r-project.org

8. Stevenson M. epiR: Tools for the Analysis of Epidemiological Data. 2019. 
Table 1: Accuracy metrics for admission AMT4 as a predictor of admission AMTS. Values (95\% confidence intervals) were calculated in R [7] using the package epiR [8].

\begin{tabular}{|c|c|c|}
\hline $\mathrm{n}=200$ & $\begin{array}{c}\text { Admission } \\
\text { AMTS<7 (+ve) }\end{array}$ & $\begin{array}{c}\text { Admission } \\
\text { AMTS >=7 (-ve) }\end{array}$ \\
\hline $\begin{array}{c}\text { Admission } \\
\text { AMT4<4 (+ve) }\end{array}$ & 60 & 13 \\
\hline $\begin{array}{l}\text { Admission } \\
\text { AMT4=4 (-ve) }\end{array}$ & 2 & 125 \\
\hline $\begin{array}{l}\text { Positive predictive value }=0.82(0.71,0.90) \\
\text { Negative predictive value }=0.98(0.94,1.00) \\
\text { Sensitivity }=0.97(0.89,1.00) \\
\text { Specificity }=0.82(0.71,0.90)\end{array}$ \\
\hline
\end{tabular}


Table 2: Accuracy metrics for admission AMT4 as a predictor of post-op AMT4. 190/200 patients were included in the analysis as 10 patients did not have a completed postoperative AMT4. Values (95\% confidence intervals) were calculated in R [7] using the package epiR [8].

\begin{tabular}{|c|c|c|}
\hline $\mathrm{n}=190$ & $\begin{array}{c}\text { Post-op } \\
\text { AMT4<4 (+ve) }\end{array}$ & $\begin{array}{c}\text { Post-op } \\
\text { AMT4=4 (-ve) }\end{array}$ \\
\hline $\begin{array}{c}\text { Admission } \\
\text { AMT4<4 (+ve) }\end{array}$ & 50 & 19 \\
\hline Admission & 8 & 132 \\
AMT4=4 (-ve) & \\
\hline $\begin{array}{l}\text { Positive predictive value }=0.72(0.60,0.83) \\
\text { Negative predictive value }=0.93(0.87 .0 .97) \\
\text { Sensitivity }=0.86(0.75,0.94) \\
\text { Specificity }=0.86(0.78,0.91)\end{array}$ \\
\hline
\end{tabular}




\section{Figure Captions}

Figure 1 - Distribution of AMTS and AMT4 scores on admission. Horizontal lines indicate the median AMTS score. Area of marker is proportional to the number of patients.

Figure 2 - Alluvial plot showing the change in patients AMT4 score between admission scoring and post-operative scoring. 


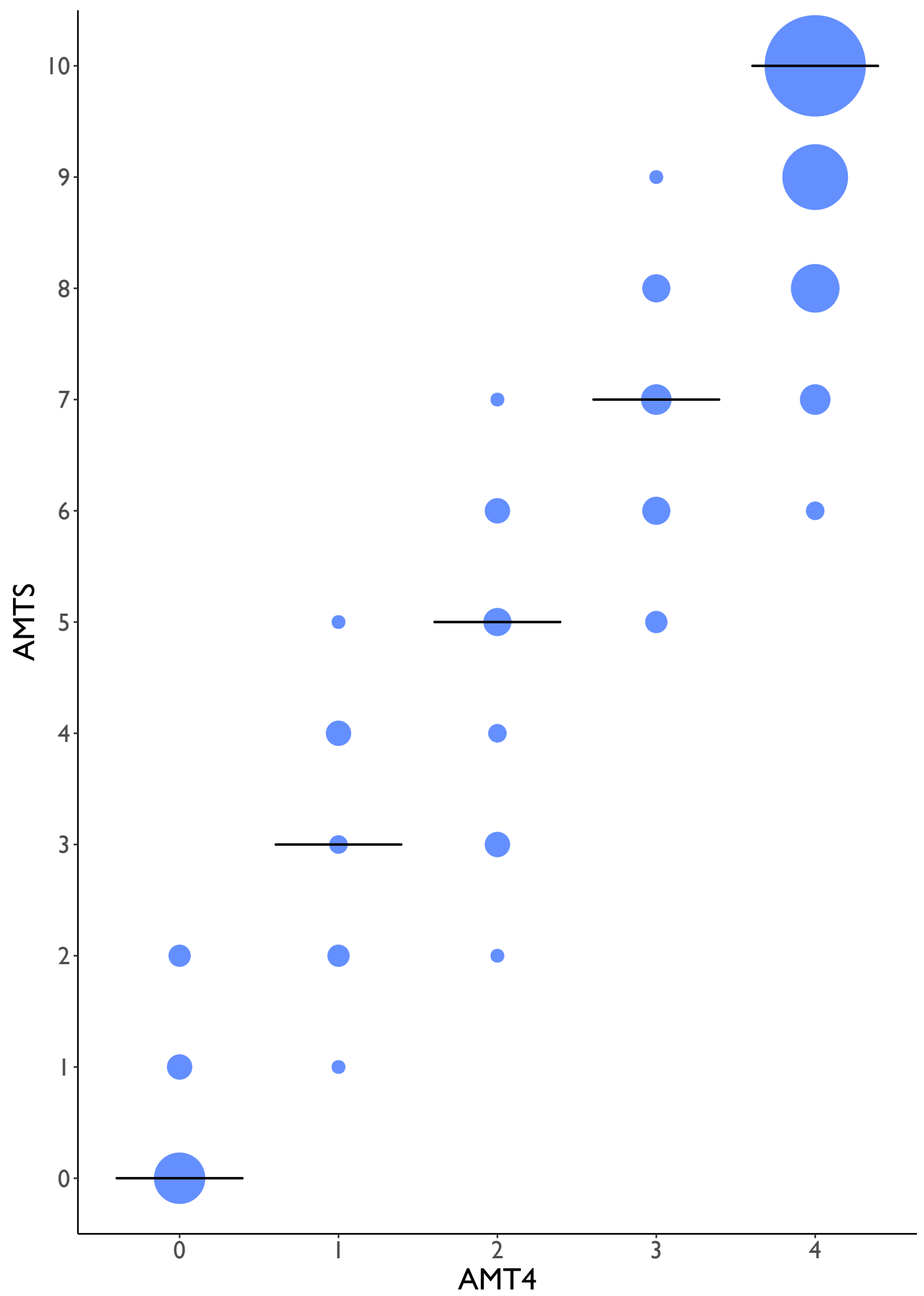

Figure 1 


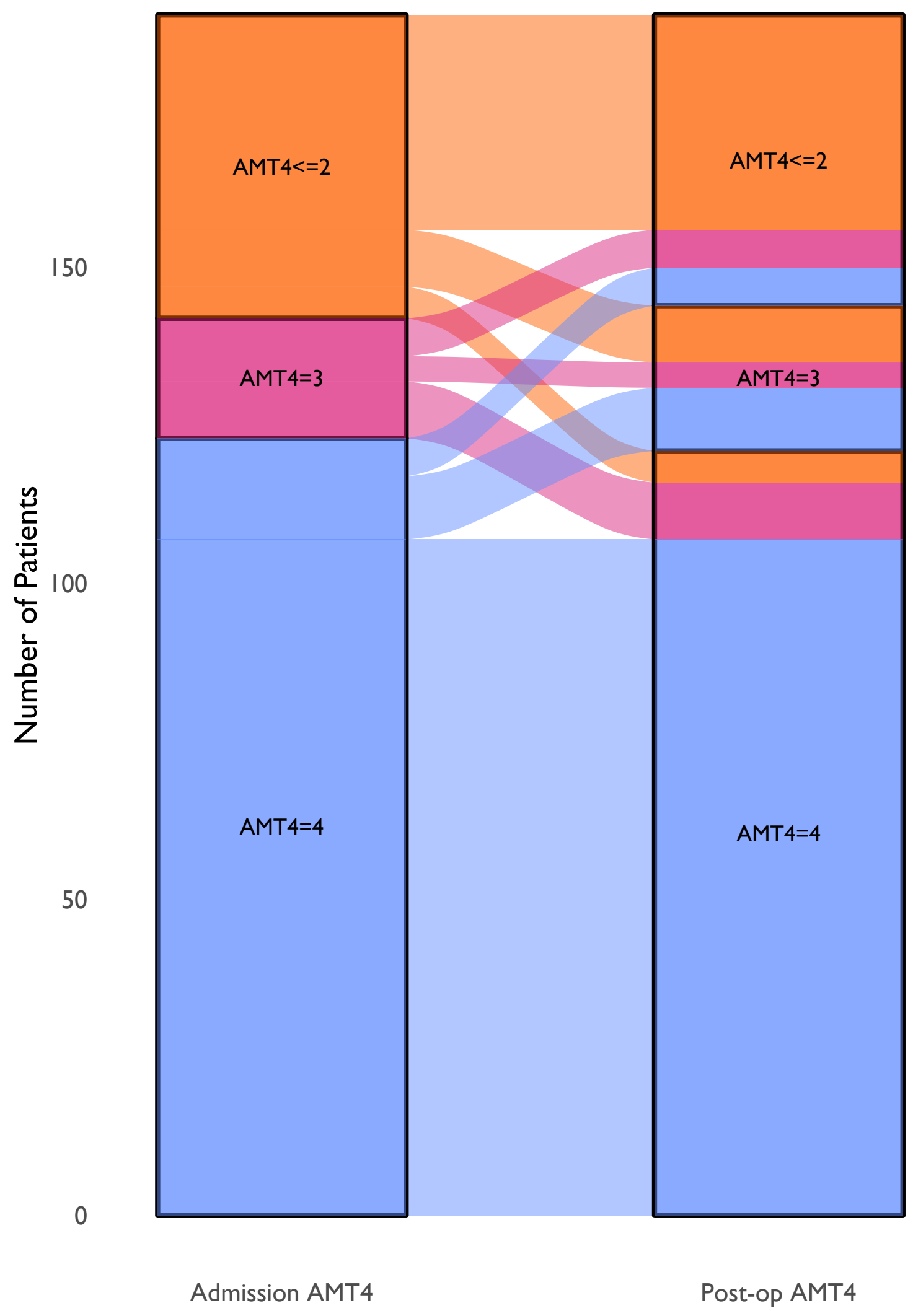

Figure 2 